\title{
The Effect of Process Parameters on Surface Finish of Metal Spun Parts
}

\author{
Peter ŠUGÁR, Jana ŠUGÁROVÁ, Ján PETROVIČ
}

\begin{abstract}
The paper brings the results of surface finish analysis of formed parts produced by CNC multi-pass conventional metal spinning. The influence of mandrel speed spinning roller feed and workpiece geometry on the surface finish of formed parts made of mild steel type of EN 10025-94 (ISO 630-80) have been studied by profile and 3D surface parameters evaluating. For the study, the full factorial design of experiment ( $\left.3^{3}\right)$ was used and ANOVA (Analysis of Variance) was carried out. It is shown that the optimal roller feed exists within the range of minimal and maximal experimental feed values and the surface roughness measured in different areas of experimental samples (radius R10, conical area, cylindrical area) indicates that the higher surface roughness occurs at the conical surfaces.
\end{abstract}

Keywords: ANOVA; metal spinning; roughness; surface

\section{INTRODUCTION}

The increasing interest in the cost-effective manufacturing of short and medium series of sheet metal products results in applying a new type of forming processes known as Incremental Sheet Forming (ISF). One of these processes, which involve forming of axisymmetric hollow parts, is sheet metal spinning. It includes conventional, shear and tube spinning processes $[1,2]$.

The main principle of sheet metal spinning is step-bystep transformation of metal blank into axisymmetric part by a roller in accordance with a mandrel shape. One or more passes of the spinning roller are used. Because of the incremental forming nature, the process brings some specific advantages. The total forming forces are reduced significantly compared to conventional sheet metal forming processes. This increases the possibilities in terms of large reductions and change in shape with less complex tooling and also reduces the required load capacity and cost of the forming machine. It also offers advantages such as short set-up time and the option of performing several process steps in one single clamping. Lastly, formed parts have high quality surface finish and improved mechanical properties [2-5].

Metal spinning is affected by many factors, including material and dimensional characteristics of the blank, roller and mandrel, mandrel speed, roller feed, temperature, lubrication, toolpath and geometry of spun part. Combinations of these variables affect the mechanics of the process and spun part surface integrity, as well.

Research focused on the study of relationship between surface finish and process parameters, which have so far been realized, to be aimed mainly on shear spinning $[3,6$, $7,8]$. The effect of machine parameters and tool on surface roughness in conventional spinning of aluminium cups has been studied in $[9,10]$. The authors report that lower feed rates, higher speeds and larger roller nose radius resulted in better surface roughness. Lower feed ratio would provide a better surface roughness, but for maintaining the original thickness of blank unchanged, feed ratios should be high. It may be necessary to find a "trade-off" feed ratio, which will guarantee maintaining the blank thickness unchanged, provide good surface roughness and prevent the material failures $[11,12]$. The empirical model of the spatial distribution of the surface roughness obtained in the friction spinning process brings Hess et al. [13]. In contrast to the study of surface topology in metal spinning by using so called phenomenological process parameters (machine and material parameters), Groche and Schäfer [14] for examination of in-process correlations introduced so called fundamental parameters (material properties, contact pressure, lubrication, shear stress and sliding velocity).

Although knowledge basis of the metal spinning principles, which helps to understand final properties of spun parts, has been developed many years by way of theoretical and experimental investigation, the process design still highly depends mainly on spinner experiences $[1,15]$. In order to increase knowledge about metal spun surface microgeometry formation the series of experiments were carried out. The effect of mandrel speed, feed ratio and workpiece geometry of the sheet on the surface finish was evaluated using experimental approach.

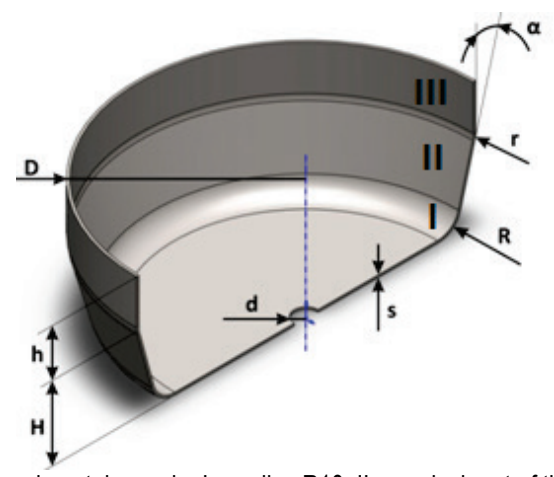

Figure 1 Experimental sample: I - radius R10, II - conical part of the workpiece, III - cylindrical part of the workpiece

Table 1 Geometrical parameters of experimental sample

\begin{tabular}{|c|c|c|c|}
\hline$D / \mathrm{mm}$ & $d / \mathrm{mm}$ & $H / \mathrm{mm}$ & $h / \mathrm{mm}$ \\
\hline 140 & 10 & 30 & 20 \\
\hline$R / \mathrm{mm}$ & $r / \mathrm{mm}$ & $\alpha /{ }^{\circ}$ & $s / \mathrm{mm}$ \\
\hline 10 & 10 & 15 & 1 \\
\hline
\end{tabular}

\section{EXPERIMENT}

The experimental samples (shape and dimensions are demonstrated in Fig. 1 and Tab. 1) were made of circular blank with an outer diameter of $D_{0}=200 \mathrm{~mm}$. The blanks were prepared by abrasive water jet cutting. The material used was mild steel according to the standards EN 1002594 (ISO 630-80). Selected mechanical properties and facilities regarding the plasticity (ultimate tensile strength 
$\left(R_{\mathrm{m}}\right), 0,2 \%$ offset yield strength $\left(R_{\mathrm{p} 0.2}\right)$, elongation $\left(A_{5}\right)$, coefficients of normal and planar anisotropy $\left(r_{s}\right),(\Delta r)$ and coefficient of material strain-hardening $(n))$ are depicted in Tab. 2.

Table 2 Mechanical properties of experimental material

\begin{tabular}{|l|c|}
\hline Ultimate tensile strength $R_{\mathrm{m}} / \mathrm{MPa}$ & 340 \\
\hline Offset yield strength $R_{\mathrm{p} 0.2} / \mathrm{MPa}$ & 235 \\
\hline Strength ratio $R_{\mathrm{p} 0.2} / R_{\mathrm{m}} /-$ & 0,69 \\
\hline Elongation $A_{5} / \%$ & 26 \\
\hline Coefficient of normal anisotropy $r_{\mathrm{s}} /-$ & 1,174 \\
\hline Coefficient of planar anisotropy $\Delta r /-$ & 0,34 \\
\hline Strain hardening coefficient $n /-$ & 0,28 \\
\hline
\end{tabular}

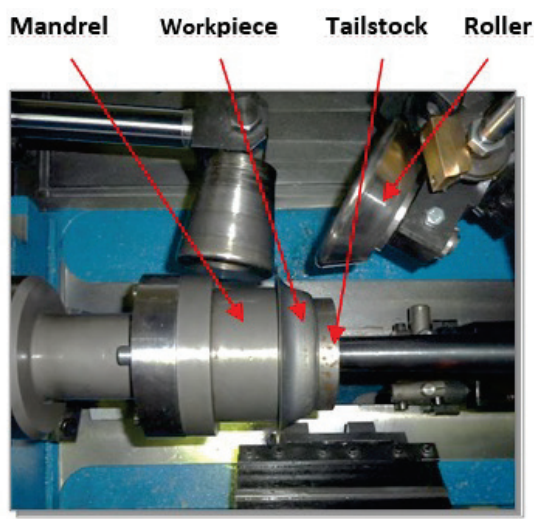

Figure 2 Experimental setup

For experimental study the DENN spinning machine of the type Zenn-80 with a Sinumeric $840-\mathrm{D}$ CNC unit has been employed. A forming tool radius $\mathrm{R} 8$ and three different levels of mandrel speed and feed ratio have been used for all of the experimental trials. The off-line designed involute $\mathrm{CNC}$ roller paths profiles have been applied: 9 movements towards the blank edge (forward passes), 3 movements towards the mandrel (backward passes) and one forward calibration pass. The lubricant oil of type AVIA GLEITBAHNÖL RSU 220 has been applied for reduction of friction and improvement of the spun parts surface quality.

Three variables, i.e. spindle speed, feed ratio and workpiece geometry at three levels $\left(3^{3}\right)$ were considered as the experimental input factors according to Tab. 3 .

Table 3 Control factors and levels

\begin{tabular}{|c|c|c|c|c|}
\hline Parameter & Sign & Level 1 & Level 2 & Level 3 \\
\hline $\begin{array}{c}\text { Mandrel speed / } \\
\text { min }^{-1}\end{array}$ & $n$ & 300 & 600 & 900 \\
\hline Feed ratio / mm & $f$ & 1 & 1.5 & 2 \\
\hline $\begin{array}{c}\text { Workpiece } \\
\text { geometry area }\end{array}$ & $w a$ & $\begin{array}{c}\text { (I) } \\
\text { radius R10 }\end{array}$ & $\begin{array}{c}\text { (II) } \\
\text { conical } \\
\text { area }\end{array}$ & $\begin{array}{c}\text { (III) } \\
\text { cylindrical } \\
\text { area }\end{array}$ \\
\hline
\end{tabular}

A standard, commercially available, Form Talysurf Intra 50 measurement system (Taylor-Hobson $\mathrm{GmbH}$ ) with no special adjustment was applied for contact roughness measurements and surface roughness parameters assessment in 2D and 3D. The measurements were taken according to the standards [16-18].

The statistical significance and the effect of the spinning process parameters and their combinations on the spun part surface profile microgeometry were analysed and documented by ANalysis Of VAriance (ANOVA). The ANOVA tables with the results of F-tests (Fisher's ratio value) and main effects plot were used to detect the significance and effect of each factor at $95 \%$ confidence level. The greater F-value than the tabulated one detected the parameters and their combinations with significant impact on the response variable.

Table 4 Results of measurement - surface roughness

\begin{tabular}{|c|c|c|c|c|}
\hline \multirow{2}{*}{$\begin{array}{l}\text { Experiment } \\
\text { number }\end{array}$} & \multicolumn{3}{|c|}{ Process parameters } & \multirow{2}{*}{$\begin{array}{c}\text { Average } \\
\text { roughness } \\
R a / \mu \mathrm{m}\end{array}$} \\
\hline & $n / \min ^{-1}$ & $f / \mathrm{mm}$ & $w a$ & \\
\hline 1 & 300 & 1 & I & 1,570 \\
\hline 2 & 300 & 1 & II & 1,650 \\
\hline 3 & 300 & 1 & III & 1,650 \\
\hline 4 & 300 & 1.5 & I & 1,000 \\
\hline 5 & 300 & 1.5 & II & 1,030 \\
\hline 6 & 300 & 1.5 & III & 0,928 \\
\hline 7 & 300 & 2 & $\mathrm{I}$ & 0,951 \\
\hline 8 & 300 & 2 & II & 0,890 \\
\hline 9 & 300 & 2 & III & 1,200 \\
\hline 10 & 600 & 1 & I & 1,580 \\
\hline 11 & 600 & 1 & II & 1,570 \\
\hline 12 & 600 & 1 & III & 1,420 \\
\hline 13 & 600 & 1.5 & $\mathrm{I}$ & 0,818 \\
\hline 14 & 600 & 1.5 & II & 1,410 \\
\hline 15 & 600 & 1.5 & III & 1,050 \\
\hline 16 & 600 & 2 & $\mathrm{I}$ & 1,040 \\
\hline 17 & 600 & 2 & II & 1,490 \\
\hline 18 & 600 & 2 & III & 1,980 \\
\hline 19 & 900 & 1 & $\mathrm{I}$ & 1,210 \\
\hline 20 & 900 & 1 & II & 1,280 \\
\hline 21 & 900 & 1 & III & 1,870 \\
\hline 22 & 900 & 1.5 & $\mathrm{I}$ & 0,920 \\
\hline 23 & 900 & 1.5 & II & 1,220 \\
\hline 24 & 900 & 1.5 & III & 0,962 \\
\hline 25 & 900 & 2 & I & 1,040 \\
\hline 26 & 900 & 2 & II & 1,840 \\
\hline 27 & 900 & 2 & III & 0,719 \\
\hline
\end{tabular}

\section{RESULTS AND DISCUSSION}

The results of the spun parts surfaces roughness measurement are listed in Tab. 4.

The images, presented in Fig. 3 to Fig. 5, give a view on the surface morphology of spun parts produced under different spinning conditions.

Fig. 6 shows the main effects plot and the results of ANOVA and $F$-test results are shown in Tab. 5.

Table 5 Results of ANOVA and F-test

\begin{tabular}{|c|c|c|c|c|c|}
\hline Source & DoF & $\begin{array}{c}\text { Sum of } \\
\text { squares }\end{array}$ & $\begin{array}{c}\text { Mean } \\
\text { square }\end{array}$ & $F$-value & $P$-value \\
\hline$n$ & 2 & 0,1458 & 0,0729 & 0,572 & 0,506 \\
\hline$f$ & 2 & 1,1191 & 0,5595 & $\mathbf{5 , 5 4} *$ & $\mathbf{0 , 0 2 0} *$ \\
\hline$w a$ & 2 & 0,3019 & 0,1509 & 1,49 & 0,263 \\
\hline$n * f$ & 4 & 0,2817 & 0,0704 & 0,70 & 0,608 \\
\hline$f * w a$ & 4 & 0,1680 & 0,0420 & 0,42 & 0,794 \\
\hline Error & 12 & 1,2121 & 0,1010 & & \\
\hline Total & 26 & 3.2286 & & & \\
\hline
\end{tabular}

$F$-ratio at confidence $95 \%: F(0.05 ; 2.12)=3.89 ; F(0.05 ; 4.12)=3.26$

$*$ significant parameter or two-way interaction, $R$-squared $=62,5 \%$

Generally it can be told that lower values of surface roughness have been observed in the area I of the spun part - radius R10 and higher values have been documented in the workpiece area II - conical part and in the area III cylindrical part. Maximal values of roughness were reached in these cases when the feed ratio was $1,5 \mathrm{~mm}$.

The surface morphologies in the conical part (II) and cylindrical part (III), compared with the area I (radius R10), are more uniform and the surfaces seen to be "porous" without high peaks and deep valleys. Unintended 
craters, randomly originated at the surface, have been observed at the surfaces in all workpiece areas (Fig. 4. and Fig. 5) In addition, on the surfaces in the area I (radius R10), a pattern of grooves provoked by the roller has been markedly visible (Fig. 3).
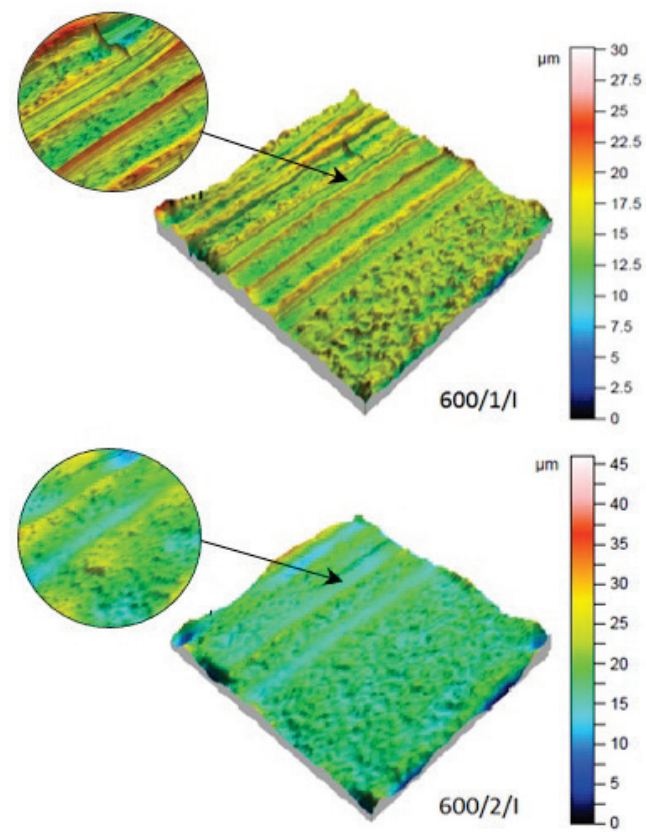

Figure 3 Spun part surface $3 \mathrm{D}$ image $-\mathrm{R} 10$ area $\left(L_{\mathrm{c}}=0,8 \mathrm{~mm}\right.$, measured area $=5 \times 5 \mathrm{~mm}) ; 600 / 1 / \mathrm{I}: n=600 \mathrm{~min}^{-1}, f=1 \mathrm{~mm}$; $600 / 2 / \mathrm{I}: n=600 \mathrm{~min}^{-1}, f=2 \mathrm{~mm}$

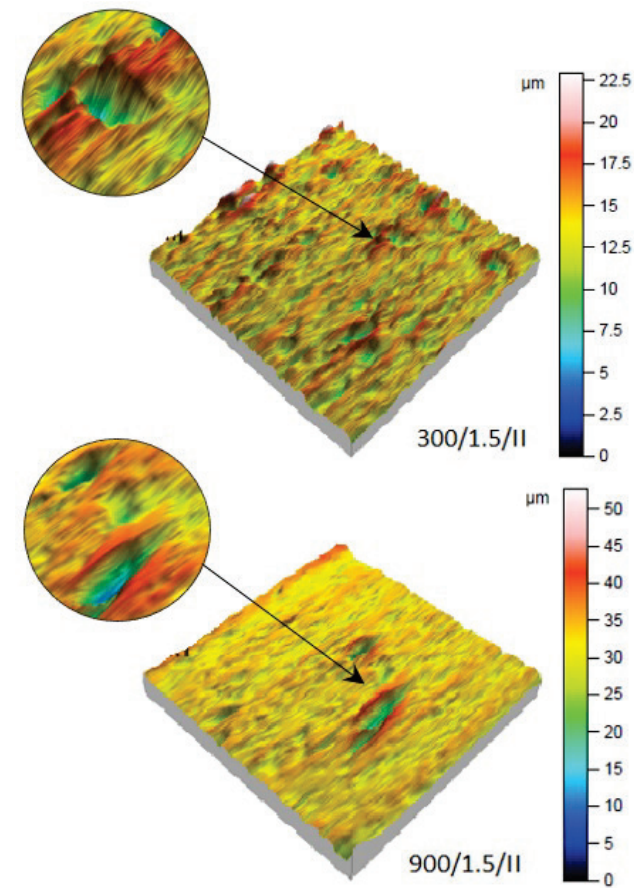

Figure 4 Spun part surface 3D image - conical area $\left(L_{\mathrm{c}}=0,8 \mathrm{~mm}\right.$, measured area $=5 \times 5 \mathrm{~mm}) ; 300 / 1.5 / \mathrm{II}: n=300 \mathrm{~min}^{-1}, f=1,5 \mathrm{~mm}$ $900 / 1.5 / \mathrm{II}: n=900 \mathrm{~min}^{-1}, f=1,5 \mathrm{~mm}$

Based on the main effects plots and ANOVA, it can be declared that feed ratio is a factor, which has relatively strong impact on the surface roughness of spun part. There is an optimal value of the feed ratio, which gives us the best surface finish. It is neither minimal nor maximal value of the feed ratio evaluated range. These results are not in agreement with the general theory based on the statement that higher feed is accompanied with higher roughness.
Regarding the phenomenon of minimal values of surface roughness in area of radius R10 it must be told that the spinning process is affected by so called phenomenological parameters (mandrel speed, feed ratio, tool geometry, formed material properties and so on), but also fundamental parameters (normal stresses under roller, shear stresses, strain states) [14]. It explains the lower values of roughness in the areas, where the higher tensile stresses are introduced in the deformed surface layers due to the intense bending.

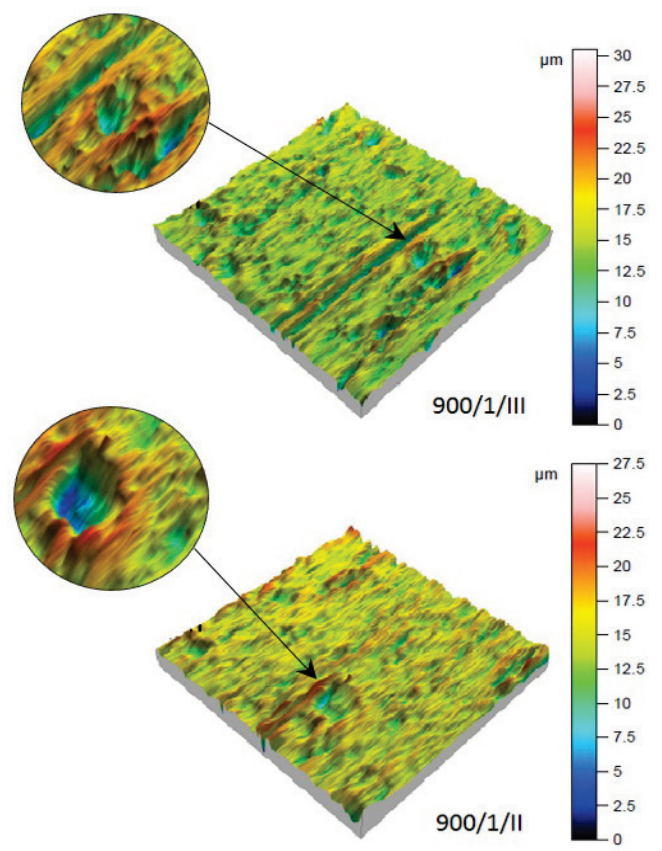

Figure 5 Spun part surface 3D image $\left(L_{\mathrm{c}}=0,8 \mathrm{~mm}\right.$, measured area $=5 \times 5$ $\mathrm{mm}) ; 900 / 1 / \mathrm{III}: n=900 \mathrm{~min}^{-1}, f=1 \mathrm{~mm}$; cylindrical area; $900 / 1 / \mathrm{II}: n=900 \mathrm{~min}^{-1}, f=1 \mathrm{~mm}$; conical area
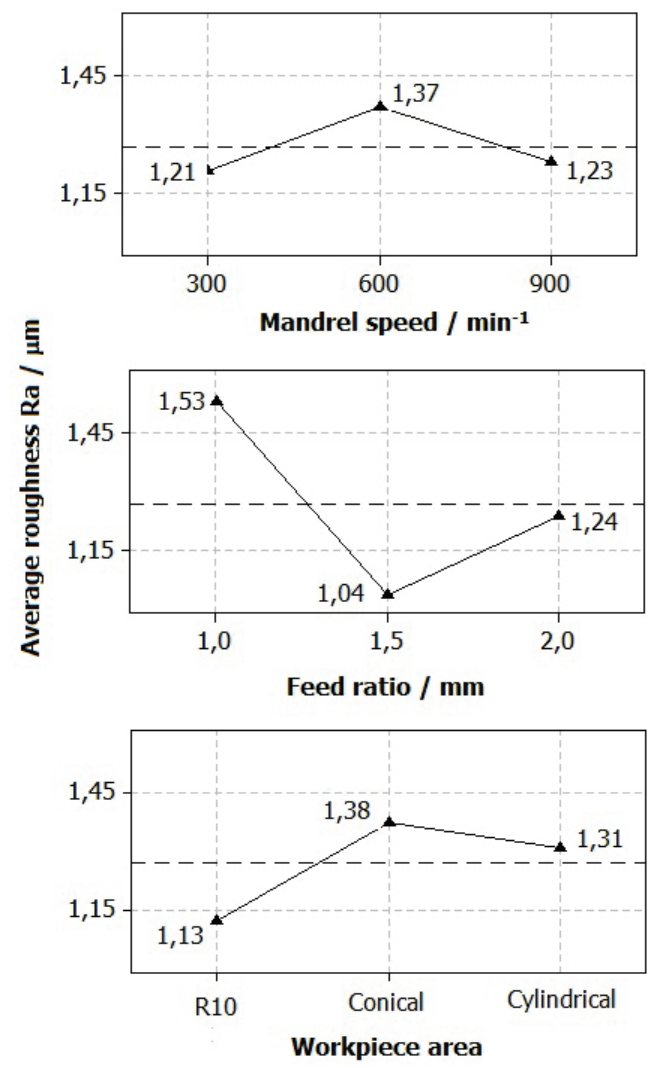

Figure 6 Main effects plots 


\section{CONCLUSION}

In this paper the effect of mandrel speed, feed ratio and workpiece geometry on spun part surface morphology and surface roughness of EN 10025-94 (ISO 630-80) steel has been studied. The major results may be summarized as follows:

- Feed ratio is a factor that intensively affected the surface roughness of the formed parts. The linear correlation between the feed ratio and roughness (higher feed is reflected in higher roughness) has not been confirmed in this case. Optimal roughness has been obtained for middle value of feed rate from the used parameter range.

- The experimental results also showed that the maximal roughness, in relation to the workpiece geometry, has been observed in the conical area of the sample. Minimal roughness has been measured in the area near the radius $\mathrm{R} 10$. It is accompanied with the fact of specific stress-strain state under roller and higher degree of tensile stresses in the part surface layer. Every sub-area of sheet is exposed to specific stress state which significantly influences the final quality of spun part surface.

- Only minimal influence of the mandrel speed variability on the final surface roughness has been reported in this study.

- The ANOVA model used in this study shows that three input variables account approximately for $62 \%$ of the variability observed in the outcome variable $(R$ squared is $62,5 \%$ ). The residual variability of $37,5 \%$ is caused by the other predictors, that are not included in this model.

\section{Acknowledgements}

The authors would like to gratefully acknowledge the Ministry of Education, Science, Research and Sport of the Slovak Republic for providing the financial support of the research project VEGA 1/0669/15 Research of laser surface texturing and its application in the sheet metal forming processes tribological conditions optimization and the project FormTool MANUNET-2014-11283: Innovative methods of sheet metal forming tools surfaces improvement - R\&D. The authors also express their sincere thanks to MSc. Eugen Eiben and MSc. Gabriel Eiben from Eiben Co Ltd. and Dr. MSc. Andrzej Matras from Cracow University of Technology, Faculty of Mechanical Engineering for their efficient help during the experiments.

\section{REFERENCES}

[1] Emmens, W. C., Sebastiani, G., \& Boogaard van den, A. H. (2010). The technology of incremental sheet forming - a brief review of the history. Journal of Material Processing Technology, 210(8), 981-997. https://doi.org/10.1016/j.jmatprotec.2010.02.014

[2] Music, O., Allwood, J. M., \& Kawai, K. A. (2010). A review of the mechanics of metal spinning. Journal of Materials Processing Technology, 210(1), 3-23. https://doi.org/10.1016/j.jmatprotec.2009.08.021

[3] Wong, C. C., Dean, T. A., \& Lin, J. (2003). A review of spinning, shear forming and flow forming processes.
International Journal of Machine Tools \& Manufacture, 43(14), 1419-1435 https://doi.org/10.1016/S0890-6955(03)00172-X

[4] Klocke, F. \& Brummer, Ch. M. (2014). Laser-assisted spinning of challenging materials. Proceedings of the $11^{\text {th }}$ International Conference on Technology of Plasticity / Nagoya, 2385-2390. https://doi.org/10.1016/i.proeng.2014.10.338

[5] Šugár, P., Šugárová, J., \& Zemko, P. (2012). Strain and strain-hardening analysis of formed parts produced by multipass metal spinning. Tehnički vjesnik, 19(1), 111-114.

[6] Chen, M. D., Hsu, R. Q., \& Fuh, K. H. (2001). Forecast of shear spinning force and surface roughness of spun cones by employing regression analysis. Int. J. of Machine Tools and Manufacture, 41(12), 1721-1734. https://doi.org/10.1016/S0890-6955(01)00039-6

[7] Ma, F., Yang, H., \& Zhang, M. (2010). Plastic deformation behaviors and their application in power spinning process of conical parts with transverse inner rib. J. of Materials Processing Technology, 210(1), 180-189. https://doi.org/10.1016/j.jmatprotec.2009.07.006

[8] Chen, M. D., Hsu, R. Q., \& Fuh, K. H. (2005). Effects of over-roll thickness on cone surface roughness in shear spinning. Forecast of shear spinning force and surface roughness of spun cones by employing regression analysis. Journal of Materials Processing Technology, 159(1), 1-8. https://doi.org/10.1016/j.jmatprotec.2003.07.017

[9] El-Khabeery, M. M., Fattouh, M., \& El-Sheikh, M. N. (1991). On the conventional simple spinning of cylindrical aluminium cups. International Journal of Machine Tool \& Manufacture, 31(2), 203-219. https://doi.org/10.1016/0890-6955(91)90005-N

[10] Venkateshwarlu, G. et al. (2013). Experimental Investigation on Spinning of Aluminum Alloy 19500 Cup. International Journal of Engineering Science and Innovative Technology, 2(1), 357-363.

[11] Wang, L. et al. (2011). Effects of roller feed ratio on wrinkling failure in conventional spinning of a cylindrical cup. Proceedings of the Institution of Mechanical Engineers, Part B, Journal of Engineering Manufacture, 225(11), 19912006. https://doi.org/10.1177/0954405410396024

[12] Wang, L. (2012). Analysis of Material Deformation and Wrinkling Failure in Conventional Metal Spinning Process. Durham theses. Durham University, http://etheses.dur.ac.uk/ 3537/ (Accessed October 2012)

[13] Hess, S. et al. (2014). Analysis of the surface roughness obtained in a friction spinning process based on empirical models. International Journal of Advanced Manufacturing Technology, 75(9-12), 1655-1665. https://doi.org/10.1007/s00170-014-6066-2

[14] Groche, P. \& Schäfer, R. (2003). Analysis of the geometrical tolerances and surface roughness of the spinning process. Process scaling, 24, BIAS, Bremen, Germany.

[15] Shinde, M., Jadhav, S., \& Gurav, K. (2014). Metal forming by sheet metal spinning enhancement of mechanical properties and parameters of metal spinning. International Journal of Engineering Development and Research, 2(2), 1352-1357.

[16] ISO 4287:1997 Geometrical product specifications (GPS) Surface texture: Profile method - Terms, definitions and surface texture parameters

[17] 4288:1996 Geometrical product specifications (GPS) Surface texture: Profile method - Rules and procedures for the assesment of surface texture

[18] ISO 3274:1996 Geometrical product specifications (GPS) Surface texture: Profile method - Nominal characteristics of contact (stylus) instruments 


\section{Contact information:}

Peter ŠUGÁR, Prof. PhD. MSc.

Slovak University of Technology,

Faculty of Material Science and Technology,

Institute of Production Engineering,

J. Bottu 25, 91724 Trnava, Slovakia

Tel. +421917367301, e-mail: peter.sugar@stuba.sk

Jana ŠugÁROVÁ, Assoc. Prof. PhD. MSc.

Slovak University of Technology,

Faculty of Material Science and Technology,

Institute of Production Engineering,

J. Bottu 25, 91724 Trnava, Slovakia

Tel. +421917367301, e-mail: jana.sugarova@stuba.sk

Ján PETROVIČ, PhD. MSc.

Eiben Co Ltd.

Továrenská 1, 97631 Vlkanová, Slovakia

Tel. +421 4847013 54, j.petrovic@eiben.sk 